\title{
Health care utilization and costs associated with direct-acting antivirals for patients with substance use disorders and chronic hepatitis C
}

\author{
Xinyi Jiang, PhD; Scott Martin Vouri, PhD, PharmD; Vakaramoko Diaby, PhD; Weihsuan Lo-Ciganic, PhD; \\ Robert Parker, PhD; and Haesuk Park, PhD
}

\section{What is already known about this subject}

- Clinical trials have reported that patients with substance use disorders (SUD) and chronic hepatitis $C$ virus (HCV) who were treated with alloral direct-acting antivirals (DAA) achieved equally high sustained virologic response rates compared with patients with HCV but without SUD.

- Access to DAA for patients with SUD and chronic HCV has been limited, and the known barriers to DAA access among these patients include, but are not limited to, payers' restrictions and providers' concerns regarding limited resources and the risk of reinfection due to continued high-risk behaviors.

- Untreated patients with chronic HCV are more likely to develop advanced liver disease (decompensated cirrhosis and hepatocellular carcinoma), which result in higher health care costs.

\author{
What this study adds \\ - Among patients with SUD and \\ chronic HCV, the use of DAA therapy \\ resulted in significant reductions in \\ liver-related costs without increasing \\ SUD-related and all-cause costs in this \\ disadvantaged population, regardless \\ of cirrhosis status. \\ - Among patients with SUD and chronic \\ HCV without cirrhosis, the use of \\ DAA therapy resulted in significant \\ reductions in SUD-related emergency \\ department and long-term care visits, \\ suggesting the extra benefit of early \\ treatment in addition to reduced liver- \\ related health care utilization \\ and costs.
}

\author{
Author affiliations \\ Xinyi Jiang, PhD, Department of \\ Pharmaceutical Outcomes \& Policy, \\ College of Pharmacy, University of Florida, \\ Gainesville. Scott Martin Vouri, PhD, \\ PharmD; Vakaramoko Diaby, PhD; Weihsuan \\ Lo-Ciganic, PhD; and Haesuk Park, PhD, \\ Department of Pharmaceutical Outcomes \& \\ Policy, Center for Drug Evaluation and Safety \\ (CoDES), College of Pharmacy, University \\ of Florida, Gainesville. Robert Parker, \\ PhD, Department of Biostatistics, College \\ of Public Health \& Health Professions, \\ College of Medicine, University of Florida, \\ Gainesville.
}

\section{AUTHOR CORRESPONDENCE:}

Haesuk Park, 352.273.6261;

HPark@cop.ufl.edu

J Manag Care Spec Pharm 2021;27(10):1388-402

Copyright $@ 2021$, Academy of Managed Care Pharmacy. All rights reserved.

health care utilization and costs among these patients is unknown.

OBJECTIVE: To compare changes in medical service utilization and costs related to liver, SUD, and all-cause morbidity in patients with SUD and HCV treated with DAAs (DAA group) vs not treated with DAAs (non-DAA group).

METHODS: We conducted a retrospective cohort study using MarketScan Commercial and Medicare Supplemental Claims databases (2012-2018) for newly diagnosed HCV treatment-naive adults with SUD. We used difference-in-differences analyses, stratified by cirrhosis status, to determine the adjusted ratio of rate ratio (RoRR) to assess the difference in the relative changes from the pre- to posttreatment periods between the 2 groups.

RESULTS: 6,266 patients with SUD and HCV were identified. Of these patients who also had cirrhosis $(n=607), 49 \%(n=298)$ initiated DAA therapy for HCV, whereas of those without cirrhosis $(n=5,659), 22 \%(n=1,219)$ 
initiated DAAs. For patients with cirrhosis $(n=607)$, the liver-related costs decreased by $\$ 6,213(95 \% \mathrm{Cl}=-\$ 8,571,-\$ 3,856)$ for the DAA group and $\$ 1,585(95 \% \mathrm{Cl}=-\$ 4,659, \$ 1,490)$ for the non-DAA group. The relative decreases in the rate of liver-related costs were larger for the DAA group than for the non-DAA group, and the relative changes between groups were significantly different $(R o R R=0.37$, $95 \% \mathrm{Cl}=0.19-0.73$ ). There was no difference in the relative changes after DAAs in the rate of SUD-related visits/costs or all-cause costs between the 2 groups. For patients without cirrhosis $(n=5,659)$, a similar association was observed. Besides, the relative decreases in the rate of SUD-related emergency department (ED) visits ( $R \circ R R=0.54$, $95 \% \mathrm{Cl}=0.38-0.77)$; SUD-related long-term care visits ( $R o R R=0.30$, $95 \% \mathrm{Cl}=0.13-0.73)$; all-cause $\mathrm{ED}$ visits ( $\mathrm{RoRR}=0.75,95 \% \mathrm{Cl}=0.64-0.88)$; and all-cause long term-care visits ( $\mathrm{RoRR}=0.36,95 \% \mathrm{Cl}=0.18-0.72)$ were larger in the DAA group than in the non-DAA group.

CONCLUSIONS: DAAs are associated with a significant decrease in the rate of SUD-related ED visits and liver-related costs without increasing the rate of all-cause costs among patients with SUD and $\mathrm{HCV}$, suggesting that the benefits of DAAs extended beyond liverrelated outcomes, especially in this disadvantaged population.

In the United States, approximately 4.1 million persons were infected with hepatitis C virus (HCV) during 2013-2016. ${ }^{1}$ Due in part to the opioid epidemic and associated injection drug use, the number of acute HCV infections increased approximately 2.9-fold from 2011 to 2018. ${ }^{2}$ As a result, patients with substance use disorders (SUD) have a high risk for the contraction and transmission of $\mathrm{HCV},{ }^{3,4}$ Approximately $60 \%-$ $90 \%$ of individuals with SUD may contract HCV during their lifetime, ${ }^{3-6}$ and more than half of all HCV infections become chronic HCV infections. ${ }^{7,8}$ However, before the advent of direct-acting antiviral agents (DAAs) in 2013, more than $90 \%$ of patients with SUD and chronic HCV were not treated for HCV because of the concerns regarding adverse effects and contraindications associated with the use of injectable interferon, a mainstay of previous HCV treatment. ${ }^{9}$ As such, untreated patients with SUD and chronic HCV frequently suffer from advanced liver disease, including decompensated cirrhosis (DCC) and hepatocellular carcinoma (HCC), which result in high health care costs. ${ }^{10}$

In late 2013, treatment for HCV changed significantly with the advent of DAAs. After the introduction of DAAs, treatment for HCV evolved into all-oral, interferon-free DAA regimens taken for only 8 to 24 weeks.,11-16 These new DAA treatment regimens provide sustained virologic response (SVR) rates of greater than $95 \%$, even for patients with SUD, as evidenced by data from clinical trials and realworld retrospective/prospective studies. ${ }^{17-23}$ As a result, the American Association for the Study of Liver Diseases
(AASLD) and the Infectious Diseases Society of America (IDSA) recommend timely DAA treatment for all patients with $\mathrm{HCV}$, including patients with SUD. ${ }^{24,25}$

Despite these recommendations, access to DAAs for patients with SUD and chronic HCV has still been limited. ${ }^{26-29}$ This divergence from the AASLD/IDSA clinical guidelines for patients with SUD and chronic HCV may reflect concerns of payers and providers..$^{29-31}$ Concerns regarding high prescription DAA costs have led private and public payers to restrict access to these medications, requiring that patients meet specific prior authorization approvals. ${ }^{32-34}$ Although some restriction criteria (eg, patient liver disease stage) have been eased, current illicit substance and/or alcohol use still pose as restrictions to accessing DAA. ${ }^{35,36}$ However, a recent study reported that among the untreated patients with chronic HCV, those with an SUD had a significantly higher risk of end-stage liver diseases compared with those without an SUD. ${ }^{37}$

In addition, the results of 2 prospective clinical trials suggested that DAAs may provide a critical opportunity to reduce risky behaviors (eg, alcohol and drug use, injecting behavior) in high-risk patients with SUD and chronic $\mathrm{HCV},{ }^{35,38}$ which suggests that the benefits of DAAs may extend beyond liver-related outcomes.

Little is known about the effect of DAA treatment on health care utilization and expenditures for patients with SUD and chronic HCV in real-world clinical practice. ${ }^{37}$ Our purpose was to assess and compare the changes in liver-related, SUD-related, and all-cause medical service utilization and costs after DAA treatment among patients with SUD and chronic HCV treated with DAAs vs those without DAAs.

\section{Methods}

\section{DATA SOURCE}

We conducted a retrospective cohort study using the IBM MarketScan Commercial Claims and Encounters Database ( $>80$ million unique beneficiaries) and Medicare Supplemental and Coordination of Benefits Database (>6 million unique beneficiaries), which include complete claims for retirees with Medicare supplemental insurance paid by employers but not those who only receive Medicare as their primary insurance, from January 2012 to December 2018. These nationwide administrative claims databases contain person-level information on diagnoses, procedures, and prescriptions across all settings, including physician outpatient office visits, hospital stays, and outpatient pharmacy claims. Health care is provided for covered employees, their spouses, and dependents, representing US individuals 


\section{TABLE 1 Baseline Characteristics for Patients With SUD and Chronic HCV Infection After Stabilized IPTW, 2013-2018}

\begin{tabular}{|c|c|c|c|c|c|c|}
\hline \multirow[b]{2}{*}{ Characteristic } & \multicolumn{3}{|c|}{$\begin{array}{l}\text { Patients with SUD and HCV } \\
\text { with cirrhosis }\end{array}$} & \multicolumn{3}{|c|}{$\begin{array}{l}\text { Patients with SUD and HCV } \\
\text { without cirrhosis }\end{array}$} \\
\hline & $\begin{array}{c}\text { DAA } \\
\text { treatment } \\
(n=298)\end{array}$ & $\begin{array}{c}\text { No } \\
\text { treatment } \\
(n=309)\end{array}$ & $\begin{array}{c}\text { Standardized } \\
\text { difference }\end{array}$ & $\begin{array}{c}\text { DAA } \\
\text { treatment } \\
(n=1,219)\end{array}$ & $\begin{array}{c}\text { No } \\
\text { treatment } \\
(n=4,440)\end{array}$ & $\begin{array}{c}\text { Standardized } \\
\text { difference }\end{array}$ \\
\hline Number of subjects (weighted) & 287 & 311 & NA & 1,218 & 4,440 & NA \\
\hline \multicolumn{7}{|l|}{ Age, years, n (\%) } \\
\hline $18-35$ & $24 \quad(8.36)$ & $26 \quad(8.36)$ & \multirow{4}{*}{-0.004} & $534(43.84)$ & $1,930(43.47)$ & \multirow{4}{*}{0.009} \\
\hline $36-50$ & $41(14.29)$ & $58 \quad(18.65)$ & & $149(12.23)$ & $619(13.94)$ & \\
\hline $51-64$ & $199 \quad(69.34)$ & $188 \quad(60.45)$ & & 476 (39.08) & $1,673(37.68)$ & \\
\hline$\geq 65$ & $22 \quad(7.67)$ & $39(12.54)$ & & $59 \quad(4.84)$ & $218 \quad(4.91)$ & \\
\hline \multicolumn{7}{|l|}{ Sex, n (\%) } \\
\hline Male & $209(72.82)$ & $228(73.31)$ & \multirow{2}{*}{0.016} & $464(38.10)$ & $1,688(38.02)$ & \multirow{2}{*}{0.001} \\
\hline Female & $78 \quad(27.18)$ & $83(26.69)$ & & $754(61.90)$ & $2,752(61.98)$ & \\
\hline \multicolumn{7}{|l|}{ Comorbidity, n (\%) } \\
\hline Diabetes & $65(22.65)$ & $74(23.79)$ & 0.031 & $165(13.55)$ & $576(12.97)$ & -0.018 \\
\hline Hypertension & $158(55.50)$ & $177(56.91)$ & 0.040 & $450(36.95)$ & $1,629(36.69)$ & -0.005 \\
\hline Dyslipidemia & $82(28.57)$ & $92(29.58)$ & 0.023 & $285(23.40)$ & $1,006(22.66)$ & -0.018 \\
\hline $\mathrm{CVD}^{\mathrm{a}}$ & $66(23.00)$ & 74 (23.79) & -0.004 & $170(13.96)$ & 608 (13.69) & -0.012 \\
\hline Chronic kidney disease & $13 \quad(4.53)$ & $14 \quad(4.50)$ & 0.001 & $37 \quad(3.04)$ & $130 \quad(2.93)$ & -0.004 \\
\hline COPD & $69(24.04)$ & $73(23.47)$ & -0.02 & $193(15.85)$ & $695(15.65)$ & -0.004 \\
\hline HIV & $\mathrm{b}$ & $\mathrm{b}$ & NA & $29 \quad(2.38)$ & $99 \quad(2.23)$ & -0.008 \\
\hline Schizophrenia/bipolar, n (\%) & $18 \quad(6.27)$ & $18 \quad(5.79)$ & -0.015 & $118 \quad(9.69)$ & $426 \quad(9.59)$ & -0.004 \\
\hline Depression & 105 (36.59) & $110(35.3 \%)$ & -0.024 & $527(43.27)$ & $1,955(44.03)$ & 0.015 \\
\hline Epilepsy & $16 \quad(5.57)$ & $15 \quad(4.82)$ & -0.026 & $41 \quad(3.37)$ & $160 \quad(3.60)$ & 0.012 \\
\hline Pregnancy & b & $\mathrm{b}$ & NA & $55 \quad(4.52)$ & $185 \quad(4.17)$ & -0.018 \\
\hline
\end{tabular}

continued on next page

covered by commercial health insurance. ${ }^{39}$ The University of Florida Institutional Review Board approved this study.

\section{STUDY COHORT}

Identification of Patients with SUD and Chronic HCV. We identified patients aged at least 18 years with a newly diagnosed chronic HCV infection using the International Classification of Diseases, Ninth/Tenth Revision, Clinical Modification (ICD-9/10-CM) codes (Supplementary Table 1, available in online article). Patients were determined to have chronic HCV if they met the criteria of a previously validated algorithm of 1 inpatient or 2 outpatient chronic $\mathrm{HCV}$ infection diagnoses on separate days within 1 year. ${ }^{40}$ We used the 2013-2018 data to establish the cohort and used the 2012 data to ensure that patients had at least 1 year as a baseline period before the first chronic HCV diagnosis. Patients were required to be HCV treatment naive (not having interferon-based or DAA-based treatments) before the first chronic HCV diagnosis and to be continuously enrolled in the health plan 1 year before and 6 months after the first chronic HCV diagnosis.

We further required patients to have a diagnosis of an SUD either within 1 year before or 6 months after the first chronic $\mathrm{HCV}$ diagnosis using the following criteria: (1) at least 1 inpatient or outpatient claim for a drug use or alcohol use disorder defined by the presence of specific ICD-9/10-CM codes (Supplementary Table 1) or (2) a claim for methadone, buprenorphine (limited to formulations approved by the US Food and Drug Administration [FDA] for opioid use disorder treatment), acamprosate, or naltrexone 

2013-2018 (continued)

\begin{tabular}{|c|c|c|c|c|c|c|}
\hline \multirow[b]{2}{*}{ Characteristic } & \multicolumn{3}{|c|}{$\begin{array}{l}\text { Patients with SUD and HCV } \\
\text { with cirrhosis }\end{array}$} & \multicolumn{3}{|c|}{$\begin{array}{l}\text { Patients with SUD and HCV } \\
\text { without cirrhosis }\end{array}$} \\
\hline & $\begin{array}{c}\text { DAA } \\
\text { treatment } \\
(n=298)\end{array}$ & $\begin{array}{c}\text { No } \\
\text { treatment } \\
(n=309)\end{array}$ & $\begin{array}{l}\text { Standardized } \\
\text { difference }\end{array}$ & $\begin{array}{c}\text { DAA } \\
\text { treatment } \\
(n=1,219)\end{array}$ & $\begin{array}{c}\text { No } \\
\text { treatment } \\
(n=4,440)\end{array}$ & $\begin{array}{l}\text { Standardized } \\
\text { difference }\end{array}$ \\
\hline \multicolumn{7}{|l|}{ Other liver disease ( 1 year before DAA index date), $n$ (\%) } \\
\hline Alcoholic liver disease & $75(26.13)$ & $90(28.94)$ & 0.063 & $24 \quad(1.97)$ & $86(1.94)$ & -0.004 \\
\hline Nonalcoholic liver disease & $52(18.12)$ & $58(18.65)$ & 0.007 & $66 \quad(5.42)$ & $254 \quad(5.72)$ & 0.011 \\
\hline Hepatitis A virus & b & b & 0.004 & b & $29(0.65)$ & 0.010 \\
\hline Hepatitis B virus & $11(3.83)$ & $14(4.50)$ & 0.033 & $20 \quad(1.64)$ & $82(1.85)$ & 0.015 \\
\hline \multicolumn{7}{|l|}{ Substance use disorders, $\mathrm{n}(\%)$} \\
\hline Opioid & $81(28.22)$ & $87(27.97)$ & -0.005 & $711(58.37)$ & $2,615(58.90)$ & 0.010 \\
\hline Other drug-related & $113(39.37)$ & $123(39.55)$ & -0.001 & $763(62.64)$ & $2,769(62.36)$ & -0.007 \\
\hline Alcohol & $185(64.46)$ & $205(65.92)$ & 0.031 & $556(45.65)$ & $2,036(45.86)$ & 0.004 \\
\hline $\begin{array}{l}\text { History of SUD-related hospitalization } \\
\text { or ED visits, } \mathrm{n}(\%)\end{array}$ & 37 (12.89) & $45(14.47)$ & 0.038 & $330(27.09)$ & $1,205(27.14)$ & 0.000 \\
\hline $\begin{array}{l}\text { Medication for opioid use disorder } \\
\text { or alcohol use disorder, } \mathrm{n}(\%)\end{array}$ & $46(16.03)$ & $50(16.08)$ & 0.002 & $414(33.99 \%)$ & $1,519(34.21)$ & 0.005 \\
\hline Pretreatment follow-up time, ${ }^{\mathrm{C}}$ mean (SD), months & $8.9 \quad(9.74)$ & $8.8(12.97)$ & 0.021 & $9.0 \quad(10.2)$ & $(9.9)$ & 0.048 \\
\hline Posttreatment follow-up time, ${ }^{\mathrm{d}}$ mean (SD), months & $16.90(12.70)$ & $13.44(5.27)$ & NA & $15.40(11.50)$ & $13.09 \quad(4.94)$ & NA \\
\hline \multicolumn{7}{|c|}{$\begin{array}{l}{ }^{b} \text { Cell size }<11 . \\
\text { cPretreatment follow-up time was estimated from the date when patients were either first diagnosed with SUD or HCV, whichever came later, until the index date. If } \\
\text { the first SUD diagnosis was after the index date, pretreatment follow-up time was estimated from the first HCV diagnosis until the index date. } \\
\text { dPosttreatment follow-up was estimated from the index date to the end of insurance eligibility, or December } 31,2018 \text {. }\end{array}$} \\
\hline \multicolumn{7}{|c|}{$\begin{array}{l}C O P D=\text { chronic obstructive pulmonary disease; } C V D=\text { cardiovascular disease; } D A A=\text { direct-acting antiviral; } E D=\text { emergency department; } H C V=\text { hepatitis } C \text { virus; } \\
\text { IPTW=inverse probability of treatment weighting; } N A=\text { not available; } S U D=\text { substance use disorder. }\end{array}$} \\
\hline
\end{tabular}

(oral and injectable) for either opioid use disorder or alcohol use disorder, as defined by the presence of the relevant National Drug Code (NDC) numbers or Current Procedural Terminology (CPT) codes (Supplementary Table 2, available in online article). ${ }^{41-44}$

We also stratified the patients with SUD and chronic HCV by baseline cirrhosis status because advanced fibrosis (cirrhosis) is one of the strongest predictors of DAA initiation and liver-related health care utilization and costs ${ }^{10,26,36,37}$

Identification of Index Date. For patients with SUD and chronic HCV who received DAA treatment, we assigned the first DAA prescription date as the index date. We defined DAAs using NDC numbers according to the FDA and AASLD/IDSA definitions for treatment-naive patients (Supplementary Table 3, available in online article).

To avoid immortal-time bias, we assigned a hypothetical index date for each untreated patient through the use of a prescription time-distribution matching approach based on the difference between the time of the first chronic $\mathrm{HCV}$ diagnosis and the dispensing time of the first DAA prescription for treated patients. ${ }^{45,46}$ We matched the overall distribution of time differences between the first HCV diagnosis and the index date of the untreated patients to that of the treated patients.

We excluded patients with a diagnosis of DCC or HCC or who had received a liver transplant during the year before the index date. We defined the baseline cirrhosis status as the diagnosis from at least 1 inpatient or 1 outpatient claim of ICD-9/10-CM codes for a cirrhosis diagnosis occurring 1 year before the index date (Supplementary Table 1). ${ }^{47}$

We defined the pretreatment period as the time from the first SUD diagnosis or the first chronic HCV diagnosis, whichever came later, until the index date (Supplementary Figure 1, available in online article). The posttreatment period started on the index date and continued until 


\section{TABLE 2}

Adjusted Liver-Related, SUD-Related, and All-Cause Medical Service Utilization PPPY Before and After DAA Treatment in the Stabilized IPTW Patients With SUD and Chronic HCV With Cirrhosis $(\mathrm{N}=607)^{\mathrm{a}}$

\begin{tabular}{|c|c|c|c|c|c|c|}
\hline & $\begin{array}{c}\text { Mean } \\
\text { adjusted } \\
\text { pretreatment }\end{array}$ & $\begin{array}{c}\text { Mean } \\
\text { adjusted } \\
\text { posttreatment }\end{array}$ & \multicolumn{2}{|c|}{$\begin{array}{l}\text { Mean adjusted } \\
\text { difference from } \\
\text { pre/post periods }\end{array}$} & \multicolumn{2}{|c|}{$\begin{array}{l}\text { RoRR for DAA } \\
\text { vs non-DAA from } \\
\text { pre/post periods }\end{array}$} \\
\hline \multicolumn{7}{|c|}{ Liver-related medical service utilization } \\
\hline \multicolumn{7}{|l|}{ Inpatient visits } \\
\hline DAA $(n=298)$ & 0.10 & 0.14 & 0.04 & $(-0.07,0.14)$ & 0.86 & $(0.29,2.56)$ \\
\hline Non-DAA $(n=309)$ & 0.32 & 0.52 & 0.20 & $(-0.05,0.44)$ & & \\
\hline \multicolumn{7}{|l|}{ ED visits } \\
\hline DAA $(n=298)$ & 0.02 & 0.04 & 0.02 & $(-0.01,0.04)$ & 1.55 & $(0.40,6.06)$ \\
\hline Non-DAA $(n=309)$ & 0.06 & 0.06 & 0.01 & $(-0.04,0.06)$ & & \\
\hline \multicolumn{7}{|l|}{ Office visits } \\
\hline $\operatorname{DAA}(n=298)$ & 4.76 & 2.87 & -1.89 & $(-2.51,-1.26)$ & 0.75 & $(0.55,1.02)$ \\
\hline Non-DAA $(n=309)$ & 1.90 & 1.53 & -0.37 & $(-0.79,0.05)$ & & \\
\hline \multicolumn{7}{|c|}{ Other outpatient visits } \\
\hline DAA $(n=298)$ & 6.11 & 4.77 & -1.34 & $(-2.28,-0.41)$ & 0.99 & $(0.72,1.35)$ \\
\hline Non-DAA $(n=309)$ & 2.72 & 2.15 & -0.57 & $(-1.15,0.007)$ & & \\
\hline \multicolumn{7}{|c|}{ SNF/long-term care visits ${ }^{b}$} \\
\hline DAA $(n=298)$ & $2.14^{\star} 10-9$ & 0.15 & 0.15 & $(-0.17,0.47)$ & 2.10 & $(0.45,9.67)$ \\
\hline Non-DAA $(n=309)$ & 0.03 & 0.08 & 0.04 & $(-0.01,0.10)$ & & \\
\hline
\end{tabular}

SUD-related medical service utilization

Inpatient visits

\begin{tabular}{l|l|l|rr|rr}
\hline DAA $(n=298)$ & 0.36 & 0.18 & -0.18 & $(-0.38,0.02)$ & 0.42 & $(0.17,1.03)$ \\
\hline Non-DAA $(n=309)$ & 0.53 & 0.63 & 0.10 & $(-0.22,0.43)$ & & \\
\hline
\end{tabular}

ED visits

\begin{tabular}{l|l|l|ll|ll}
\hline DAA $(n=298)$ & 0.07 & 0.10 & 0.04 & $(-0.06,0.14)$ & 1.27 & $(0.41,3.89)$ \\
\hline Non-DAA $(n=309)$ & 0.13 & 0.16 & 0.03 & $(-0.04,0.10)$ & & \\
\hline
\end{tabular}

Office visits

\begin{tabular}{l|l|l|ll|ll}
\hline DAA $(n=298)$ & 0.83 & 0.50 & -0.33 & $(-0.65,-0.005)$ & 0.73 & $(0.44,1.22)$ \\
\hline Non-DAA $(n=309)$ & 1.24 & 1.02 & -0.21 & $(-0.56,0.13)$ & & \\
\hline
\end{tabular}

Other outpatient visits

\begin{tabular}{l|l|l|lr|ll}
\hline DAA $(\mathrm{n}=298)$ & 6.98 & 3.17 & -3.81 & $(-6.46,-1.16)$ & 0.56 & $(0.24,1.35)$ \\
\hline Non-DAA $(\mathrm{n}=309)$ & 5.25 & 4.56 & -0.69 & $(-3.23,1.85)$ & & \\
\hline
\end{tabular}

SNF/long-term care visits

\begin{tabular}{l|l|l|ll|ll}
\hline DAA $(\mathrm{n}=298)$ & 0.059 & 0.008 & -0.05 & $(-0.12,0.02)$ & 0.66 & $(0.09,5.07)$ \\
\hline Non-DAA $(\mathrm{n}=309)$ & 0.194 & 0.038 & -0.16 & $(-0.38,0.07)$ & &
\end{tabular}

continued on next page the end of insurance eligibility or December 31, 2018, whichever came first (Supplementary Figure 1).

\section{STUDY OUTCOMES}

Medical Service Utilization and Costs. We applied a standardized algorithm to obtain medical service utilization and related costs from inpatient and outpatient claims for the pretreatment and posttreatment periods separately. ${ }^{48}$ The visit types included hospitalization, emergency department (ED), outpatient office, skilled nursing facility (SNF)/long-term care (eg, hospice and residential substance abuse facility), and other nonpharmacy outpatient services (eg, laboratory outpatient chemistry tests).

For medical service utilization, we calculated the average number of medical visits related to liver, SUD, and all-cause morbidity. Liver-related and SUD-related morbidities were identified via primary claims with any liver-related diagnosis or procedure (ie, HCV, cirrhosis, DCC, HCC, DCC-related procedure, and liver transplant) defined by the presence of the relevant ICD-9/10-CM/CPT codes or a primary diagnosis of SUD (Supplementary Table 1). ${ }^{40,47}$

Medical costs were defined as the amounts that payers paid plus member cost sharing for services related to the same causes of morbidity. Given that the cost distribution was skewed with extreme values, we excluded patients with total pretreatment and posttreatment all-cause medical costs at or greater than the $99 \%$ percentile of the total costs outliers (ie, >\$642,898 per person; Supplementary Figure 2, available in online article). ${ }^{49,50}$ We adjusted all costs to 2018 U.S. dollars using an annual $3 \%$ inflation rate.

\section{STATISTICAL ANALYSIS}

We used a multivariable logistic regression model to estimate the propensity 


\section{TABLE 2}

\begin{tabular}{|c|c|c|c|c|}
\hline & $\begin{array}{c}\text { Mean } \\
\text { adjusted } \\
\text { pretreatment }\end{array}$ & $\begin{array}{c}\text { Mean } \\
\text { adjusted } \\
\text { posttreatment }\end{array}$ & $\begin{array}{l}\text { Mean adjusted } \\
\text { difference from } \\
\text { pre/post periods }\end{array}$ & $\begin{array}{l}\text { RoRR for DAA } \\
\text { vs non-DAA from } \\
\text { pre/post periods }\end{array}$ \\
\hline \multicolumn{5}{|c|}{ All-cause medical service utilization } \\
\hline \multicolumn{5}{|l|}{ Inpatient visits } \\
\hline DAA $(n=298)$ & 1.41 & 0.91 & $-0.49 \quad(-0.93,-0.06)$ & $0.74 \quad(0.48,1.13)$ \\
\hline Non-DAA $(n=309)$ & 2.80 & 2.46 & $(-0.98,0.31)$ & \\
\hline \multicolumn{5}{|l|}{ ED visits } \\
\hline DAA $(n=298)$ & 1.33 & 1.13 & $(-0.56,0.16)$ & $0.75 \quad(0.52,1.06)$ \\
\hline Non-DAA $(n=309)$ & 2.13 & 2.44 & $(-0.17,0.78)$ & \\
\hline \multicolumn{5}{|l|}{ Office visits } \\
\hline DAA $(n=298)$ & 16.10 & 12.96 & $-3.14(-4.64,-1.65)$ & $0.70 \quad(0.60,0.81)$ \\
\hline Non-DAA $(n=309)$ & 12.39 & 14.31 & $(0.39,3.44)$ & \\
\hline \multicolumn{5}{|c|}{ Other outpatient visits } \\
\hline DAA $(n=298)$ & 27.44 & 23.99 & $-3.45 \quad(-6.58,-0.32)$ & $0.75 \quad(0.64,0.90)$ \\
\hline Non-DAA $(n=309)$ & 22.24 & 25.76 & $(0.66,6.39)$ & \\
\hline \multicolumn{5}{|c|}{ SNF/long-term care visits } \\
\hline DAA $(n=298)$ & 0.45 & 0.87 & $0.42 \quad(-0.26,1.09)$ & $3.96(1.34,11.73)$ \\
\hline Non-DAA $(n=309)$ & 2.41 & 1.17 & $-1.24(-2.35,-0.13)$ & \\
\hline \multicolumn{5}{|c|}{ 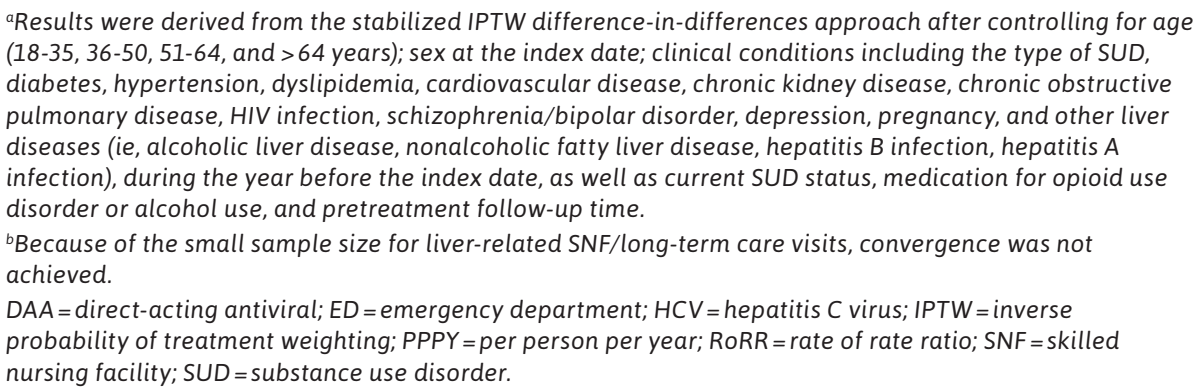 } \\
\hline
\end{tabular}

score to adjust for differences in baseline characteristics between patients with SUD and chronic HCV treated with DAAs (DAA group) and those not treated with DAAs (non-DAA group) stratified by baseline cirrhosis status. This propensity score represented the probability of the patient obtaining the DAA therapy, depending on the baseline covariates that were associated with $\mathrm{HCV}$ treatment and that may have had a high impact on the cost of health care and the utilization of services. ${ }^{51,52}$ These covariates are listed in Supplementary Table 4 (available in online article)..$^{53}$

We then calculated each individual's stabilized inverse probability of treatment weighting (IPTW) using the propensity score. ${ }^{52,54}$ We considered the baseline characteristics to be balanced if the standardized difference of a given covariate between the 2 groups was less than 0.1. ${ }^{52,55}$
We first estimated the relative changes in the rate of medical service utilization and costs from the pretreatment to the posttreatment periods within the DAA and non-DAA groups. We then compared the differences in the relative changes in rate of utilization and costs between the DAA and non-DAA groups using a difference-in-differences analysis. ${ }^{56,57}$ This approach controls for secular trends in outcomes of interest, as well as the unobserved fixed effects of patients with SUD and chronic HCV (eg, motivation to engage in health system such as for SUD treatment). ${ }^{58}$

The stabilized IPTW differencein-differences model can control for underlying trends in factors that could influence our selected outcomes and minimize selection bias. ${ }^{59,60}$ We tested the parallel pretreatment trends assumption in a regression model to meet the key assumption of difference-in-differences (for detailed information, see Supplementary Appendix 1, available in online article). ${ }^{56,61}$

To evaluate medical care utilization, we used zero-inflated negative binomial regression models for $\mathrm{HCV}$ and SUD-related medical service utilization and a generalized linear model (GLM) with a negative binomial distribution and a log link for allcause medical service utilization (for additional detailed information about modeling choices, see Supplementary Appendix 2A, available in online article).

To estimate medical costs, we used 2-part models for estimating HCV and SUD-related costs, which consisted of (1) logistic regression to predict the probability of having health care costs greater than zero and (2) a GLM with a gamma distribution and a log link. ${ }^{62}$ In addition, for all-cause costs estimation, a GLM with a gamma distribution and a log link were used. ${ }^{49}$ 
TABLE 3 Adjusted Liver-Related, SUD-Related, and All-Cause Medical Service Utilization PPPY Before and After DAA Treatment in the Stabilized IPTW Patients With SUD and Chronic HCV Without Cirrhosis $(\mathrm{N}=5,659)^{\text {a }}$

\begin{tabular}{|c|c|c|c|c|}
\hline & $\begin{array}{c}\text { Mean } \\
\text { adjusted } \\
\text { pretreatment }\end{array}$ & $\begin{array}{c}\text { Mean } \\
\text { adjusted } \\
\text { posttreatment }\end{array}$ & $\begin{array}{l}\text { Mean adjusted } \\
\text { difference from } \\
\text { pre/post periods }\end{array}$ & $\begin{array}{c}\text { RoRR for DAA } \\
\text { vs non-DAA from } \\
\text { pre/post periods }\end{array}$ \\
\hline \multicolumn{5}{|c|}{ Liver-related medical service utilization } \\
\hline \multicolumn{5}{|l|}{ Inpatient visits } \\
\hline DAA $(n=1,219)$ & 0.06 & 0.02 & $-0.04 \quad(-0.07,-0.01)$ & $0.51(0.27,0.96)$ \\
\hline Non-DAA $(n=4,440)$ & 0.09 & 0.06 & $-0.03(-0.04,-0.01)$ & \\
\hline
\end{tabular}

ED visits

\begin{tabular}{l|l|l|l|ll}
\hline DAA $(n=1,219)$ & 0.005 & 0.01 & $0.005(-0.003,0.012)$ & $1.32(0.38,4.62)$ \\
\hline Non-DAA $(n=4,440)$ & 0.005 & 0.008 & $0.002(-0.002,0.007)$ & \\
\hline
\end{tabular}

Office visits

\begin{tabular}{l|l|l|ll|ll}
\hline DAA $(n=1,219)$ & 3.26 & 1.73 & -1.53 & $(-1.74,-1.32)$ & 1.11 & $(0.99,1.26)$ \\
\hline Non-DAA $(n=4,440)$ & 0.93 & 0.44 & -0.49 & $(-0.54,-0.43)$ & & \\
\hline
\end{tabular}

Other outpatient visits

\begin{tabular}{l|l|l|ll|l}
\hline DAA $(n=1,219)$ & 3.52 & 2.40 & -1.11 & $(-1.35,-0.88)$ & $1.31(1.17,1.47)$ \\
\hline Non-DAA $(n=4,440)$ & 1.04 & 0.54 & -0.50 & $(-0.56,-0.44)$ & \\
\hline
\end{tabular}

SNF/long-term care visits

\begin{tabular}{l|l|l|l|l}
\hline DAA $(n=1,219)$ & 0.001 & 0.002 & $0.001(-0.002,0.004)$ & $1.19(0.07,19.47)$ \\
\hline Non-DAA $(n=4,440)$ & 0.004 & 0.008 & $0.004(-0.006,0.013)$ & \\
\hline
\end{tabular}

SUD-related medical service utilization

Inpatient visits

\begin{tabular}{l|l|l|rr|rr}
\hline DAA $(n=1,219)$ & 0.62 & 0.51 & -0.11 & $(-0.27,0.05)$ & $0.81(0.59,1.12)$ \\
\hline Non-DAA $(n=4,440)$ & 0.83 & 0.84 & 0.01 & $(-0.08,0.10)$ & & \\
\hline
\end{tabular}

ED visits

\begin{tabular}{l|l|l|rr|r}
\hline DAA $(n=1,219)$ & 0.18 & 0.14 & -0.04 & $(-0.09,0.02)$ & $0.54(0.38,0.77)$ \\
\hline Non-DAA $(n=4,440)$ & 0.22 & 0.33 & 0.11 & $(0.06,0.16)$ & \\
\hline
\end{tabular}

Office visits

\begin{tabular}{l|l|l|rr|r}
\hline DAA $(n=1,219)$ & 1.27 & 1.12 & -0.16 & $(-0.42,0.11)$ & $0.83(0.64,1.06)$ \\
\hline Non-DAA $(n=4,440)$ & 1.37 & 1.46 & 0.09 & $(-0.08,0.25)$ & \\
\hline
\end{tabular}

Other outpatient visits

\begin{tabular}{l|r|r|rr|rr}
\hline DAA $(n=1,219)$ & 10.53 & 9.85 & -0.68 & $(-2.60,1.25)$ & 0.84 & $(0.67,1.04)$ \\
\hline Non-DAA $(n=4,440)$ & 9.80 & 11.25 & 1.45 & $(0.57,2.33)$ & \\
\hline
\end{tabular}

SNF/long-term care visits

\begin{tabular}{l|l|l|rr|r}
\hline DAA $(n=1,219)$ & 0.15 & 0.05 & -0.10 & $(-0.19,-0.01)$ & $0.30(0.13,0.73)$ \\
\hline Non-DAA $(n=4,440)$ & 0.16 & 0.18 & 0.02 & $(-0.05,0.08)$ & \\
\hline
\end{tabular}

continued on next page
All regression models included an interaction term between time (pretreatment vs posttreatment periods) and DAA status (DAA group vs non-DAA group), which we added to the model after the stabilized IPTWs and the control for covariates mentioned previously. The difference in the adjusted relative changes in the outcomes of interest from the pretreatment period to the posttreatment period between the DAA group and the non-DAA group were presented by the ratio of rate ratio (RoRR), which is the exponential of the interaction term (for additional detailed information, see Supplementary Appendix 2B, available in online article). ${ }^{63}$

Given that our outcomes of interest were not independent for each patient over time, we calculated clustered standard errors and the corresponding $95 \%$ CIs. ${ }^{61,64,65}$ We also conducted a sensitivity analysis based on any SUDrelated services costs (eg, urine drug tests, behavioral health therapy, and respiratory therapy). We used 2-tailed tests with the significance level set at 0.05. All statistical analyses were performed using Stata software, version 13 (StataCorp) and SAS version 9.4 (SAS Institute).

\section{Results}

\section{PATIENT CHARACTERISTICS}

We identified 6,266 newly diagnosed treatment-naive chronic HCV patients with SUD who met our eligibility criteria (Supplementary Figure 2). Of the patients with SUD and chronic HCV who also had cirrhosis $(n=607), 49 \%$ $(n=298)$ initiated DAAs for their HCV, whereas of those without cirrhosis $(n=5,659), 22 \%(n=1,219)$ initiated DAAs. The differences in baseline characteristics associated with DAA treatment for patients with SUD and chronic HCV stratified by cirrhosis status before stabilized IPTW are 


\section{TABLE 3}

\begin{tabular}{|c|c|c|c|c|}
\hline & $\begin{array}{l}\text { Mean } \\
\text { adjusted } \\
\text { pretreatment }\end{array}$ & $\begin{array}{l}\text { Mean } \\
\text { adjusted } \\
\text { posttreatment }\end{array}$ & $\begin{array}{l}\text { Mean adjusted } \\
\text { difference from } \\
\text { pre/post periods }\end{array}$ & $\begin{array}{l}\text { RoRR for DAA } \\
\text { vs non-DAA from } \\
\text { pre/post periods }\end{array}$ \\
\hline \multicolumn{5}{|c|}{ All-cause medical service utilization } \\
\hline \multicolumn{5}{|l|}{ Inpatient visits } \\
\hline DAA $(n=1,219)$ & 1.26 & 0.89 & $-0.38 \quad(-0.56,-0.19)$ & $0.83(0.69,1.01)$ \\
\hline Non-DAA $(n=4,440)$ & 2.24 & 1.89 & $-0.35 \quad(-0.49,-0.21)$ & \\
\hline \multicolumn{5}{|l|}{ ED visits } \\
\hline DAA $(n=1,219)$ & 1.14 & 1.05 & $-0.1 \quad(-0.25,0.07)$ & $0.75(0.64,0.88)$ \\
\hline Non-DAA $(n=4,440)$ & 1.78 & 2.17 & $(0.27,0.51)$ & \\
\hline \multicolumn{5}{|l|}{ Office visits } \\
\hline DAA $(n=1,219)$ & 12.73 & 10.86 & $-1.87 \quad(-2.49,-1.26)$ & $0.79(0.74,0.84)$ \\
\hline Non-DAA $(n=4,440)$ & 9.47 & 10.27 & $(0.49,1.12)$ & \\
\hline \multicolumn{5}{|l|}{ Other outpatient visits } \\
\hline DAA $(n=1,219)$ & 27.57 & 25.28 & $-2.29 \quad(-4.32,-0.26)$ & $0.78(0.72,0.85)$ \\
\hline Non-DAA $(n=4,440)$ & 23.10 & 27.15 & $(3.04,5.07)$ & \\
\hline \multicolumn{5}{|c|}{ SNF/long-term care visits } \\
\hline DAA $(n=1,219)$ & 0.76 & 0.38 & $(-0.77,0.01)$ & $0.36(0.18,0.72)$ \\
\hline Non-DAA $(n=4,440)$ & 1.01 & 1.42 & $(0.05,0.77)$ & \\
\hline \multicolumn{5}{|c|}{$\begin{array}{l}\text { aResults were derived from the stabilized IPTW difference-in-differences approach after controlling for age } \\
\text { (18-35, 36-50,51-64, and >64 years); sex at the index date; clinical conditions including the type of SUD, } \\
\text { diabetes, hypertension, dyslipidemia, cardiovascular disease, chronic kidney disease, chronic obstructive } \\
\text { pulmonary disease, HIV infection, schizophrenia/bipolar disorder, depression, pregnancy, and other liver } \\
\text { diseases (ie, alcoholic liver disease, nonalcoholic fatty liver disease, hepatitis B infection, hepatitis A } \\
\text { infection), during the year before the index date, as well as current SUD status, medication for opioid use } \\
\text { disorder or alcohol use, and pretreatment follow-up time. }\end{array}$} \\
\hline \multicolumn{5}{|c|}{$\begin{array}{l}D A A=\text { direct-acting antiviral; } E D=\text { emergency department; } H C V=\text { hepatitis } C \text { virus; } I P T W=\text { inverse } \\
\text { probability of treatment weighting; } P P P Y=\text { per person per year; } R=R R=\text { rate of rate ratio; } S N F=\text { skilled } \\
\text { nursing facility; SUD = substance use disorder. }\end{array}$} \\
\hline
\end{tabular}

summarized in Supplementary Table 5 (available in online article).

After we applied the stabilized IPTW, the DAA and non-DAA groups achieved an acceptable balance (with a standardized difference of each covariate $<0.1$ ), regardless of cirrhosis status (Table 1). The majority in the DAA and non-DAA groups with cirrhosis were male (73\% in both groups); were aged 51-64 years (DAA: 69\% vs non-DAA: 61\%); had hypertension
(DAA: $56 \%$ vs non-DAA: $57 \%$ ); and had alcohol use disorder (64\% vs. 66\%). Less than one-fifth of each group had a history of SUD-related hospitalizations or ED visits (13\% vs $14 \%$ ) or received medication treatment for SUD (16\% in both groups).

The majority of the patients in the DAA and non-DAA groups without cirrhosis were female $(62 \%$ in both groups); aged $18-35$ years (DAA: $44 \%$ vs non-DAA: 43\%); had depression (DAA:
43\% vs non-DAA: 44\%); and had opioid use disorder (DAA: $58 \%$ vs non-DAA: $59 \%$ ). Approximately $27 \%$ of each group had a history of SUD-related hospitalizations or ED visits, and one-third received medications for SUD.

\section{ANNUAL MEDICAL SERVICE UTILIZATION}

The changes in the mean annual adjusted liver-related, SUD-related, and all-cause visits per person from the pre- to posttreatment periods of the DAA and non-DAA groups among patients with cirrhosis are shown in Table 2. For patients with SUD and chronic HCV who had cirrhosis $(\mathrm{n}=607)$, there were no significant differences in the relative changes of rate of utilization of liver-related or SUDrelated medical services between the 2 groups (Table 2). As for all-cause visits, all-cause office visits decreased by 3.1 visits $(95 \% \mathrm{CI}=-4.6,-1.7)$ for the DAA group and increased by 1.9 visits $(95 \% \mathrm{CI}=0.39,3.44)$ for the non-DAA group. The all-cause other outpatient visits decreased by 3.5 visits (95\% $\mathrm{CI}=-6.6,-0.3)$ for the DAA group and increased by 3.5 visits $(95 \% \mathrm{CI}=0.66$, 6.39) for the non-DAA group.

The statistically significant differences in relative changes (in rate ratio scale) between groups from the pre- to posttreatment periods in the rate of all-cause office visits (rate ratio: 0.80 vs 1.15 , RoRR: $0.70,95 \%$ $\mathrm{CI}=0.60,0.81)$ and rate of all-cause other outpatient visits (rate ratio: 0.87 vs 1.16, RoRR: $0.75,95 \% \mathrm{CI}=0.64,0.90$ ) showed decreases for the DAA group and increases for the non-DAA group (Table 2).

For patients with SUD and chronic HCV without cirrhosis $(n=5,659)$, the liver-related hospitalizations decreased by 0.04 visits $(95 \%$ $\mathrm{CI}=-0.07,-0.01)$ for the DAA group and 0.03 visits $(95 \% \mathrm{CI}=-0.04,-0.01)$ for the non-DAA group (Table 3). The statistically significant differences in 


\section{FIGURE 1 Adjusted Medical Service Costs Among the Stabilized IPTW Patients With SUD and Chronic HCV and Cirrhosis: Liver-Related Costs ${ }^{\mathrm{a}, \mathrm{b}}$}

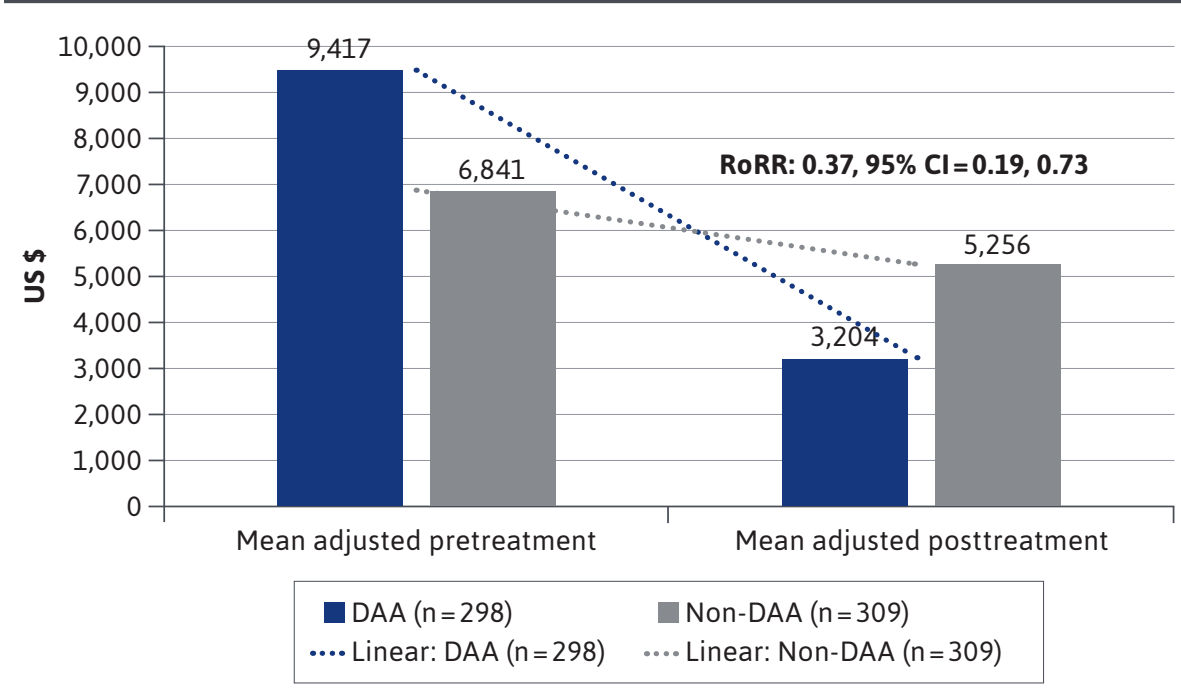

aResults were derived from the stabilized IPTW difference-in-differences approach after controlling for age (18-35, 36-50, 51-64, and >64 years); sex at the index date; clinical conditions including the type of SUD, diabetes, hypertension, dyslipidemia, cardiovascular disease, chronic kidney disease, chronic obstructive pulmonary disease, HIV infection, schizophrenia/bipolar disorder, depression, pregnancy, and other liver diseases (ie, alcoholic liver disease, nonalcoholic fatty liver disease, hepatitis B infection, hepatitis A infection), during the year before the index date, as well as current SUD status, medication for opioid use disorder or alcohol use, and pretreatment follow-up time.

${ }^{b}$ Costs were adjusted to 2018 U.S. dollars using an annual $3 \%$ inflation rate.

$D A A=$ direct-acting antiviral; $H C V=$ hepatitis $C$ virus; IPTW = inverse probability of treatment weighting; RoRR = rate of rate ratio; SUD = substance use disorder

relative changes between groups from the pre- to posttreatment periods in rate of liver-related hospitalizations (rate ratio: 0.33 vs 0.67 , RoRR: 0.51 , $95 \% \mathrm{CI}=0.27,0.96)$ showed that the rate of liver-related hospitalizations decreased more in the DAA group than in the non-DAA group. On the other hand, the rate of liver-related other outpatient visits in the DAA group decreased statistical significantly less compared with the non-DAA group (rate ratio: 0.68 vs 0.52 , RoRR: 1.31 , $95 \% \mathrm{CI}=1.17,1.47)$.

In addition, the DAA group without cirrhosis was found to be associated with greater relative decreases in the rate of SUD-related ED visits (rate ratio: 0.78 vs 1.50 , RoRR: $0.54,95 \%$
$\mathrm{CI}=0.38, \quad 0.77) ; \quad$ SUD-related SNF / long-term care visits (rate ratio: 0.33 vs 1.13, RoRR: $0.30,95 \% \mathrm{CI}=0.13,0.73$ ); all-cause ED visits (rate ratio: 0.92 vs 1.22, RoRR: $0.75,95 \% \mathrm{CI}=0.64,0.88$ ); and all-cause SNF/long-term care visits (rate ratio: 0.50 vs 1.41 , RoRR: $0.36,95 \% \mathrm{CI}=0.18,0.72)$ from the preto posttreatment periods that were statistically significant compared with the relative changes in the nonDAA group without cirrhosis (Table 3).

\section{ANNUAL MEDICAL SERVICE COSTS}

Among patients with SUD and chronic HCV who had cirrhosis, the changes in the mean adjusted liver-related, SUD-related, and all-cause medical services per person per year (PPPY) costs from the pre- to posttreatment periods for the DAA and non-DAA groups are summarized in Figure 1 and Supplementary Figure 3 (available in online article). Overall, for patients with SUD and chronic HCV and cirrhosis, the liver-related PPPY cost decreased by $\$ 6,213$ (95\% CI $=-\$ 8,571$, $-3,856)$ for the DAA group and $\$ 1,585$ (95\% CI $=-\$ 4,659$, \$1,490) for the nonDAA group; the relative decreases in the rate of liver-related PPPY cost were larger for the DAA group than for the non-DAA group, and the relative changes between groups were significantly different (rate ratio: 0.34 vs 0.77 , RoRR: $0.37,95 \% \mathrm{CI}=0.19,0.73$; Figure 1). The principal driver of this cost reduction was liver-related other outpatient PPPY costs (rate ratio: 0.24 vs 0.58, RoRR: 0.34, 95\% CI = [0.19, 0.62; Supplementary Table 6, available in online article).

There were no significant differences in relative changes from the pre- to posttreatment periods in rate of SUD-related PPPY costs (rate ratio: 1.31 vs 1.07 , RoRR: $1.40,95 \% \mathrm{CI}=0.67$, 2.92; Supplementary Figure 3A) or in rate of all-cause PPPY costs (rate ratio: 0.68 vs 0.54 , RoRR: $1.26,95 \% \mathrm{CI}=0.89$, 1.78 ) between the DAA group and nonDAA group (Supplementary Figure 3B).

Similarly, the patients with SUD and chronic HCV who did not have cirrhosis showed a larger relative decrease from the pre- to posttreatment periods in rate of liver-related PPPY costs in the DAA group than in the non-DAA group, and the relative changes were significantly different between the groups (rate ratio: 0.19 vs. 0.25 , RoRR: $0.54,95 \% \mathrm{CI}=0.42$, 0.70 ; Figure 2). The principal driver of this cost reduction was also liverrelated other outpatient PPPY costs (rate ratio: 0.17 vs 0.27 , RoRR: $0.44,95 \%$ $\mathrm{CI}=0.33,0.58$; Supplementary Table 7, available in online article). The differences in the relative changes from the pre- to posttreatment periods in 


\section{FIGURE 2 Adjusted Medical Service Costs Among the Stabilized IPTW Patients With SUD and Chronic HCV but Without Cirrhosis: Liver-Related Costs ${ }^{\mathrm{a}, \mathrm{b}}$}

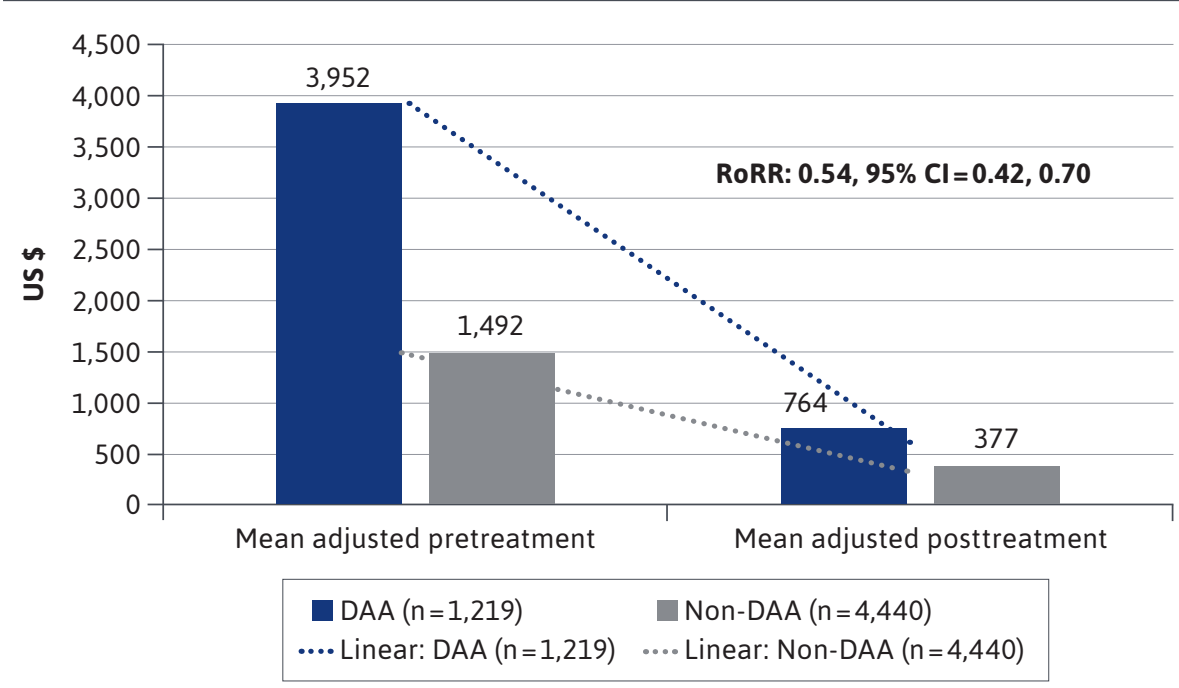

${ }^{a}$ Results were derived from the stabilized IPTW difference-in-differences approach after controlling for age (18-35, 36-50, 51-64, and > 64 years); sex at the index date; clinical conditions including the type of SUD, diabetes, hypertension, dyslipidemia, cardiovascular disease, chronic kidney disease, chronic obstructive pulmonary disease, HIV infection, schizophrenia/bipolar disorder, depression, pregnancy, and other liver diseases (ie, alcoholic liver disease, nonalcoholic fatty liver disease, hepatitis B infection, hepatitis $A$ infection), during the year before the index date, as well as current SUD status, medication for opioid use disorder or alcohol use, and pretreatment follow-up time.

${ }^{b}$ Costs were adjusted to 2018 U.S. dollars using an annual $3 \%$ inflation rate.

$D A A=$ direct-acting antiviral; $H C V=$ hepatitis $C$ virus; IPTW = inverse probability of treatment weighting; RoRR = rate of rate ratio; SUD =substance use disorder.

rate of the SUD-related PPPY costs in the DAA group and the non-DAA group were not significantly different (rate ratio: 0.82 vs 0.74 , RoRR: 1.17, 95\% CI =0.89, 1.54; Supplementary Figure 4A, available in online article).

Although there were statistically significant differences in the absolute decreases in all-cause PPPY costs in the DAA group and the non-DAA group separately from the pre- to posttreatment periods (decreased by $\$ 16,226,95 \% \quad C I=-\$ 20,770,-\$ 11,681$, for the DAA group and $\$ 29,625,95 \%$ $\mathrm{CI}=-\$ 33,025,-\$ 26,226$, for the nonDAA group), the relative decrease in the rate of all-cause PPPY costs was smaller for the DAA group compared with that of the non-DAA group (rate ratio: 0.63 vs 0.54 , RoRR: 1.18, 95\% $\mathrm{CI}=1.02$, 1.37; Supplementary Figure 4B, available in online article), largely due to a greater reduction in the all-cause hospitalization PPPY cost from the pre- to posttreatment periods for the non-DAA group $(\$ 17,195)$ than for the DAA group (\$6,250; RoRR: 1.20, 95\% $\mathrm{CI}=0.91,1.58$; Supplementary Table 7). This reduction compensated for that in the all-cause other outpatient PPPY costs for the DAA group (\$10,609 for the DAA group vs $\$ 9,402$ for the nonDAA group; RoRR: 0.98, 95\% CI=0.83, 1.15; Supplementary Table 7).

There were no significant coefficients for the interaction terms of time and DAA treatment in the pretreatment period for the liver-related medical services visits $(P=0.28)$ and other outcomes, suggesting that the parallel assumption holds (Supplementary Table 8, available in online article).

\section{SENSITIVITY ANALYSIS}

In a separate sensitivity analysis examining any SUD-related services (eg, urine drug tests), there was no significant difference in the relative changes from the pre- to posttreatment periods in the rate of costs of any SUD-related services between the DAA and non-DAA groups (Supplementary Table 9, available in online article).

\section{Discussion}

This retrospective cohort study provides real-world evidence on the changes from the pre- to posttreatment periods in liver-related, SUD-related, and all-cause medical service utilization and costs among commercially insured treatmentnaive chronic $\mathrm{HCV}$ patients with SUD treated with and without DAAs. For patients without cirrhosis, DAA treatment significantly reduced the rate of liver-related hospitalizations, SUD-related ED visits, SUD-related SNF/long-term care visits, and allcause visits (except for all-cause inpatient visits).

For patients with cirrhosis, DAA treatment led to more significant relative reductions in the rate of all-cause office visits and other outpatient visits, whereas there was no statistically difference in relative changes in the rate of liver-related or SUDrelated visits or other all-cause visits after DAAs between the 2 groups. We found that, regardless of cirrhosis status, patients who received DAAs were associated with significantly greater relative reductions in the rate of liver-related costs than their nonDAA peers; however, no significant 
differences in relative changes of the rate of SUD-related costs or all-cause costs were found.

Although less than a quarter of the all patients with SUD and chronic HCV initiated DAA therapy, our finding of greater relative reductions in the rate of liver-related costs in this group are encouraging. Previous researchers have reported a decreased risk of developing end-stage liver disease and reduced liver-related expenditures for a privately insured or Medicare-insured chronically HCV-infected population (with cirrhosis) who underwent DAA treatment. ${ }^{10,66}$ Nevertheless, little was known about whether this conclusion held among patients with SUD and chronic HCV.

Our results further suggest that, even for patients with SUD and chronic HCV with access, barriers exist that are potentially related to providers' concerns regarding patients' risky behaviors and reinfections. ${ }^{35}$ DAA treatment was associated with a decrease in liver-related health care utilization and liver-related medical services costs. Thus, our results provide evidence for physicians and payers that expanding access to DAA treatment for patients with SUD and chronic HCV may be effective in reducing liverrelated costs.

According to the Centers for Disease Control and Prevention, SUD-related ED visits continued to rise from 2016 to 2017 because of nonfatal overdoses from prescription and illicit drugs. ${ }^{67,68}$ In light of this information, our finding that SUD-related ED visits and long-term care visits had a significantly greater reduction in the rate for the DAA group than for the non-DAA group among patients with SUD and chronic HCV without cirrhosis may suggest that the benefits of DAAs extend beyond liver-related outcomes, with treatment having a positive effect on patients' highrisk behaviors, especially among those without cirrhosis. ${ }^{69}$

On the one hand, our finding of notable decreasing trends in SUD-related visits counters the argument that treating patients with SUD and chronic HCV with DAAs could lead to increased injection drug use or risky behaviors. ${ }^{31,69,70}$ On the other hand, it is also likely that the reduction in SUD-related visits reflects that patients in the DAA group are ready to make health changes and are more willing to accept harm reduction education (eg, sterile syringe access). ${ }^{35,71}$ We controlled for history of SUD pharmacotherapy to mitigate the imbalance between the two groups during the pretreatment period. However, future research is needed that includes patient attitudes and readiness for HCV treatment in the model.

\section{STRENGTHS AND LIMITATIONS}

Our study has several strengths. First, this study has methodological strength as a result of using prescription time-distribution matching to adjust time to initiate DAA treatment after diagnosis and the stabilized IPTW difference-in-differences model controlling for underlying trends in factors that could influence our selected outcomes. The difference-in-differences model reduced bias in the posttreatment period comparison that could be the result from inherent differences between adults with SUD and chronic HCV treated with DAAs and those without DAAs, as well as biases from comparisons over time in the treatment group that could be the result of trends from other causes of the outcome. This approach has not been applied in previous economic analyses of the effects of DAA therapy in patients with HCV and should be used in future economic analyses, given its robust methodological strengths..$^{58,72}$

Second, to our knowledge, our work provides the first real-world evidence about the favorable current health care resource utilization and cost patterns among patients with SUD and chronic HCV, which can be used for future economic models that focus on this population with barriers to care..$^{72}$

Our study results also have several limitations. First, we used ICD-9/10-CM codes and pharmacy claims to identify patients with SUD, chronic HCV, and cirrhosis, which may have led to an underestimation of the number of targeted individuals and a lack of granularity on the severity and current status of the disease (eg, fibrosis staging and SUD with illicit injectable opioids vs prescription opioids), although validated algorithms were used. ${ }^{40,73}$ Also, our results may have suffered from potential selection bias despite our use of stabilized IPTW to balance the 2 groups. ${ }^{51}$

Second, given the current reimbursement requirements, it is possible that our population might have had to abstain from alcohol or injectable drug use for a certain period of time to be able to obtain the insurance approvals necessary to cover the costs of DAA treatment. ${ }^{29,65}$ Thus, our DAA group may have been more likely to be former substance users, but our non-DAA group may have been more likely to be current substance users. We attempted to mitigate this limitation by controlling for SUD-related ED or inpatient visits at baseline. In addition, several patients were excluded because of unconfirmed continuous eligibility, which is required for ascertainment of baseline covariates and previous medication use.

Third, selection bias could have been introduced by the inclusion of individuals with continuous eligibility of at least 1 year, considering that several patients with SUD might have encountered a coverage loss. Therefore, our results from the privately insured population may not be generalizable to those who are uninsured and other populations (eg, Medicare and Medicaid). ${ }^{74}$ 
Finally, we could not ascertain several important variables, such as patient race/ethnicity and current injection drug use behavior, in the propensity score, which may have had an effect on the outcomes.

\section{Conclusions}

Among treatment-naive chronic HCV patients with SUD, the use of DAA therapy resulted in significant reductions in the rate of liver-related costs without increasing the rate of SUD-related and all-cause costs in this population with barriers to care, regardless of cirrhosis status. We found a significant decline in the rate of SUD-related ED and longterm care visits for the DAA group compared with the non-DAA group among those without cirrhosis, suggesting the value of early treatment of patients with SUD and chronic HCV. Future work is needed on the strategies necessary to improve access to DAA treatment, especially for SUD subpopulations, to meet World Health Organization and US goals for eliminating hepatitis C by 2030 .

\section{DISCLOSURES}

Research reported in this publication was supported in part by the National Institute on Drug Abuse of the National Institutes of Health (K01DA045618). The funder did not have a role in the design, the execution, the analyses, the interpretation of the data, or the decision to submit the results of this study. The authors have no potential conflicts of interest.

\section{ACKNOWLEDGMENTS}

The authors thank Debbie L. Wilson, PhD (University of Florida), for providing editorial assistance in the preparation of this manuscript.

\section{REFERENCES}

1. Hofmeister MG, Rosenthal EM, Barker LK, et al. Estimating prevalence of hepatitis $\mathrm{C}$ virus infection in the United States, 2013-2016. Hepatology. 2019;69(3):1020-31.

2. Centers for Disease Control and Prevention. Surveillance for viral hepatitis - United States, 2017. November 14, 2019. Accessed July 31, 2021. https://www.cdc. gov/hepatitis/statistics/2017surveillance/ index.htm

3. Ti L, Parent S, Socías ME. Integrated models of care for people living with hepatitis $\mathrm{C}$ virus and a substance use disorder: protocol for a systematic review. JMIR Res Protoc. 2018;7(5):e122.

4. Fill M, Sizemore L, Rickles M, et al. Epidemiology and risk factors for hepatitis $\mathrm{C}$ virus infection in a highprevalence population. Epidemiol Infect. 2018;146(4):508-14.

5. Schaefer M, Mauss S. Hepatitis C treatment in patients with drug addiction: clinical management of interferonalpha-associated psychiatric side effects. Curr Drug Abuse Rev. 2008;1(2):177-87.

6. Fuster D, Sanvisens A, Bolao F, Rivas I, Tor J, Muga R. Alcohol use disorder and its impact on chronic hepatitis $\mathrm{C}$ virus and human immunodeficiency virus infections. World J Hepatol. 2016;8(31):1295-308.

7. Wang W, Lo Re V III, Guo Y, Xiao H, Brown J, Park H. Impact of hepatitis C virus treatment on the risk of non-hepatic cancers among hepatitis C virus-infected patients in the US. Aliment Pharmacol Ther. 2020;52(10):1592-602.

8. Ngo-Metzger Q, Mabry-Hernandez I, Heslin KC, Weiss AJ, Mummert A, Bierman AS. Characteristics of inpatient stays involving hepatitis C, 2005-2014. HCUP Statistical Brief \#232. November 2017. Agency for Healthcare Research and Quality, Rockville, MD. Accessed July 31, 2021. https://www.hcup-us.ahrq.gov/ reports/statbriefs/sb232-Hepatitis-CHospital-Stays-Trends.jsp
9. Gonzalez SA, Fierer DS, Talal AH. Medical and behavioral approaches to engage people who inject drugs into care for hepatitis $C$ virus infection. Addict Disord Their Treat. 2017;16 (2 Suppl 1):S1-S23.

10. Park H, Wang W, Henry L, Nelson DR. Impact of all-oral direct-acting antivirals on clinical and economic outcomes in patients with chronic hepatitis $\mathrm{C}$ in the United States. Hepatology. 2019;69(3):1032-45.

11. Gigi E, Sinakos E, Lalla T, Vrettou E, Orphanou E, Raptopoulou M. Treatment of intravenous drug users with chronic hepatitis C: treatment response, compliance and side effects. Hippokratia. 2007;11(4):196-98.

12. Coffin PO, Corcorran MA. Treatment of $\mathrm{HCV}$ in persons with substance use. Hepatitis C Online. June 21, 2020. Accessed July 20, 2020. https://www. hepatitisc.uw.edu/pdf/key-populationssituations/treatment-substance-use/ core-concept/all

13. American Association for the Study of Liver Disease and Infectious Disease Society of America. HCV guidance: recommendations for testing, managing, and treating hepatitis C. Key populations: identification and management of $\mathrm{HCV}$ in people who inject drugs. Updated November 6, 2019. Accessed July 31, 2021. https://www.hcvguidelines.org/ unique-populations/pwid

14. Islam N, Krajden M, Shoveller J, et al. Incidence, risk factors, and prevention of hepatitis $\mathrm{C}$ reinfection: a populationbased cohort study. Lancet Gastroenterol Hepatol. 2017;2(3):200-10.

15. Grebely J, Dalgard O, Conway B, et al. Sofosbuvir and velpatasvir for hepatitis $\mathrm{C}$ virus infection in people with recent injection drug use (SIMPLIFY): an openlabel, single-arm, phase 4, multicentre trial. Lancet Gastroenterol Hepatol. 2018;3(3):153-61.

16. Mishra P, Chen M. Direct-acting antivirals for chronic hepatitis C: can drug properties signal potential for liver injury? Gastroenterology. 2017;152(6):1270-74. 
17. Grebely J, Bruggmann P, Treloar C, et al. Expanding access to prevention, care and treatment for hepatitis $C$ virus infection among people who inject drugs. Int J Drug Policy. 2015;26(10):893-98.

18. Dore GJ, Altice F, Litwin AH, et al. Elbasvir-grazoprevir to treat hepatitis $\mathrm{C}$ virus infection in persons receiving opioid agonist therapy: a randomized trial. Ann Intern Med. 2016;165(9):625-34.

19. Lalezari J, Sullivan JG, Varunok P, et al. Ombitasvir/paritaprevir/r and dasabuvir plus ribavirin in HCV genotype 1-infected patients on methadone or buprenorphine. J Hepatol. 2015;63(2):364-69.

20. Grebely J, Feld JJ, Wyles D, et al. Sofosbuvir-based direct-acting antiviral therapies for $\mathrm{HCV}$ in people receiving opioid substitution therapy: an analysis of phase 3 studies. Open Forum Infect Dis. 2018;5(2):ofy001.

21. Butner JL, Gupta N, Fabian C, Henry S, Shi JM, Tetrault JM. Onsite treatment of $\mathrm{HCV}$ infection with direct acting antivirals within an opioid treatment program. J Subst Abuse Treat. 2017;75:49-53.

22. Christensen S, Buggisch P, Mauss S, et al. Direct-acting antiviral treatment of chronic HCV-infected patients on opioid substitution therapy: still a concern in clinical practice? Addiction. 2018;113(5):868-82.

23. Ottman AA, Townsend ML,

Hashem MG, Britt RB. Impact of substance use disorder on the rate of sustained virological response in veterans with chronic hepatitis $\mathrm{C}$ treated with directacting antivirals. Ann Pharmacother. 2019;53(6):581-87.

24. American Association for the Study of Liver Disease and Infectious Disease Society of America. HCV guidance: recommendations for testing, managing, and treating hepatitis $\mathrm{C}$. When and in whom to initiate HCV therapy. Updated November 6, 2019. Accessed August 1, 2021. https://www.hcvguidelines.org/ evaluate/when-whom

25. Chhatwal J, Wang X, Ayer T, et al. Hepatitis $\mathrm{C}$ disease burden in the United States in the era of oral direct-acting antivirals. Hepatology. 2016;64(5):1442-50.
26. Jiang X, Song HJ, Wang W, et al. The use of all-oral direct-acting antivirals in hepatitis $\mathrm{C}$ virus-infected patients with substance use disorders. J Manag Care Spec Pharm. 2021;27(7):873-81. doi: 10.18553/jmcp.2021.27.7.873

27. Socías ME, Ti L, Wood E, et al. Disparities in uptake of direct-acting antiviral therapy for hepatitis $\mathrm{C}$ among people who inject drugs in a Canadian setting. Liver Int. 2019;39(8):1400-07.

28. Falade-Nwulia O, Irvin R, Merkow A, et al. Barriers and facilitators of hepatitis $\mathrm{C}$ treatment uptake among people who inject drugs enrolled in opioid treatment programs in Baltimore. J Subst Abuse Treat. 2019;100:45-51.

29. Park H, Song HJ, Jiang X, Henry L, Cook RL, Nelson DR. Direct-acting antiviral treatment use remains low among Florida Medicaid beneficiaries with chronic hepatitis C. Hepatology Commun. 2020;5(2):203-216.

30. Linas BP, Nolen S. A guide to the economics of hepatitis $\mathrm{C}$ virus cure in 2017. Infect Dis Clin North Am. 2018;32(2):447-59.

31. Asher AK, Portillo CJ, Cooper BA, Dawson-Rose C, Vlahov D, Page KA. Clinicians' views of hepatitis $C$ virus treatment candidacy with directacting antiviral regimens for people who inject drugs. Subst Use Misuse. 2016;51(9):1218-23.

32. Barua S, Greenwald R, Grebely J, Dore GJ, Swan T, Taylor LE. Restrictions for Medicaid reimbursement of sofosbuvir for the treatment of hepatitis $C$ virus infection in the United States. Ann Intern Med. 2015;163(3):215-23.

33. Do A, Mittal Y, Liapakis A, et al. Drug authorization for sofosbuvir/ledipasvir (Harvoni) for chronic HCV infection in a real-world cohort: a new barrier in the HCV care cascade. PLoS One. 2015;10(8):e0135645.

34. Canary LA, Klevens RM, Holmberg SD. Limited access to new hepatitis $C$ virus treatment under state Medicaid programs. Ann Intern Med. 2015;163(3):226-28.
35. Artenie AA, Cunningham EB, Dore GJ, et al. Patterns of drug, alcohol use and injection equipment sharing among people with recent injecting drug use or receiving opioid agonist treatment during and following hepatitis $\mathrm{C}$ virus treatment with direct-acting antiviral therapies: an international study. Clin Infect Dis. 2020;70(11):2369-76.

36. National Viral Hepatitis Roundtable, Center for Health Law and Policy Innovation. Hepatitis C: the state of Medicaid access: 2017 National Summary Report. October 23, 2017. Accessed August 1, 2021. https://www.chlpi.org/ wp-content/uploads/2013/12/State-ofHepC_2017_FINAL.pdf

37. Park H, Jiang X, Song HJ, et al. The impact of direct-acting antiviral therapy on end stage liver disease among individuals with chronic hepatitis $\mathrm{C}$ and substance use disorders. Hepatology. February 5, 2021. Online ahead of print. Accessed August 1, 2021. https://doi. org/10.1002/hep.31732

38. Rosenthal E, Hill K, Nussdorf L, et al. Collocation of buprenorphine with $\mathrm{HCV}$ treatment to improve adherence and reduce harm in PWID with $\mathrm{HCV}$ : preliminary data from the ANCHOR study. J Hepatol. 2018;68(1):S51.

39. IBM Watson Health. IBM MarketScan Research Databases for health services researchers. White paper. April 2019. Accessed July 20, 2020. https://www.ibm. com/downloads/cas/6KNYVVQ2

40. Niu B, Forde KA, Goldberg DS. Coding algorithms for identifying patients with cirrhosis and hepatitis B or C virus using administrative data. Pharmacoepidemiol Drug Saf. 2015;24(1):107-11.

41. Lo-Ciganic WH, Gellad WF, Gordon AJ, et al. Association between trajectories of buprenorphine treatment and emergency department and in-patient utilization. Addiction. 2016;111(5):892-902.

42. Reus VI, Fochtmann LJ, Bukstein O, et al. The American Psychiatric Association practice guideline for the pharmacological treatment of patients with alcohol use disorder. Focus (Am Psychiatr Publ). 2019;17(2):158-62. 
43. Morgan JR, Schackman BR, Leff JA, Linas BP, Walley AY. Injectable naltrexone, oral naltrexone, and buprenorphine utilization and discontinuation among individuals treated for opioid use disorder in a United States commercially insured population. J Subst Abuse Treat. 2018;85:90-96.

44. Thomas CP, Ritter GA, Harris AH, Garnick DW, Freedman KI, Herbert B. Applying American Society of Addiction Medicine performance measures in commercial health insurance and services data. J Addict Med. 2018;12(4):287-94.

45. Harvey R, Jankus DD, Mosley D. PH02 Random assignment of proxy event dates to unexposed individuals in observational studies: an automated technique using SAS. Paper presented at: MidWest SAS Users Group; September 16-18, 2012; Minneapolis, MN. Accessed August 1, 2021. https://www.mwsug.org/proceedings/2012/PH/MWSUG-2012-PH02.pdf

46. Zhou Z, Rahme E, Abrahamowicz M, Pilote L. Survival bias associated with time-to-treatment initiation in drug effectiveness evaluation: a comparison of methods. Am J Epidemiol. 2005;162(10):1016-23.

47. Lu M, Chacra W, Rabin D, et al. Validity of an automated algorithm using diagnosis and procedure codes to identify decompensated cirrhosis using electronic health records. Clin Epidemiol. 2017;9:369-76. doi:10.2147/CLEP.S136134

48. Voss EA, Ma Q, Ryan PB. The impact of standardizing the definition of visits on the consistency of multi-database observational health research. BMC Med Res Methodol. 2015;15(1):13.

49. Deb P, Norton EC. Modeling health care expenditures and use. Annu Rev Public Health. 2018;39:489-505.

50. Zhang D, Prabhu VS, Marcella SW. Attributable healthcare resource utilization and costs for patients with primary and recurrent Clostridium difficile infection in the United States. Clin Infect Dis. 2018;66(9):1326-32.
51. Lu CY, Ross-Degnan D, Zhang F, et al. Cost burden of hepatitis $\mathrm{C}$ virus treatment in commercially insured patients. Am J Manag Care. 2019;25(12):e379-e387.

52. Austin PC, Stuart EA. Moving towards best practice when using inverse probability of treatment weighting (IPTW) using the propensity score to estimate causal treatment effects in observational studies. Stat Med. 2015;34(28):3661-79.

53. Brookhart MA, Wyss R, Layton JB, Stürmer T. Propensity score methods for confounding control in nonexperimental research. Circulation. 2013;6(5):604-11.

54. Stürmer T, Wyss R, Glynn RJ, Brookhart MA. Propensity scores for confounder adjustment when assessing the effects of medical interventions using nonexperimental study designs. J Int Med. 2014;275(6):570-80.

55. Austin PC. Balance diagnostics for comparing the distribution of baseline covariates between treatment groups in propensity-score matched samples. Stat Med. 2009;28(25):3083-107.

56. Dimick JB, Ryan AM. Methods for evaluating changes in health care policy: the difference-in-differences approach. JAMA. 2014;312(22):2401-02.

57. Zhou H, Taber C, Arcona S, Li Y. Difference-in-differences method in comparative effectiveness research: utility with unbalanced groups. Appl Health Econ Health Policy. 2016;14(4):419-29.

58. Crown WH. Propensity-score matching in economic analyses: comparison with regression models, instrumental variables, residual inclusion, differencesin-differences, and decomposition methods. App Health Econ Health Policy. 2014;12(1):7-18.

59. Stuart EA, Huskamp HA, Duckworth K, et al. Using propensity scores in difference-in-differences models to estimate the effects of a policy change. Health Serv Outcomes Res Methodol. 2014;14(4):166-82.

60. Xu S, Ross C, Raebel MA, Shetterly S, Blanchette C, Smith D. Use of stabilized inverse propensity scores as weights to directly estimate relative risk and its confidence intervals. Value Health. 2010;13(2):273-77.
61. Abouk R, Grosse SD, Ailes EC Oster ME. Association of US state implementation of newborn screening policies for critical congenital heart disease with early infant cardiac deaths. JAMA. 2017;318(21):2111-18.

62. Mullahy J. Specification and testing of some modified count data models. J Econom. 1986;33(3):341-65.

63. Karaca-Mandic P, Norton EC, Dowd B. Interaction terms in nonlinear models. Health Serv Res. 2012;47(1 Pt 1):255-74.

64. Bertrand M, Duflo E, Mullainathan S. How much should we trust differencesin-differences estimates? Q J Econ. 2004;119(1):249-75.

65. Beil H, Feinberg RK, Patel SV, Romaire MA. Behavioral health integration with primary care: implementation experience and impacts from the State Innovation Model round 1 states. Milbank Q. 2019;97(2):543-82.

66. Jung J, Feldman R, Kalidindi Y, Riley T. Association of direct-acting antiviral therapy for hepatitis $\mathrm{C}$ with after-treatment costs among Medicare beneficiaries. JAMA Network Open. 2020;3(6):e208081-e208081.

67. Centers for Disease Control and Prevention. 2018 Annual surveillance report of drug-related risks and outcomes-United States. August 31, 2018. Accessed August 1, 2021. https://www. cdc.gov/drugoverdose/pdf/pubs/2018cdc-drug-surveillance-report.pdf

68. Centers for Disease Control and Prevention. Opioid overdoses treated in emergency departments. CDC Vitalsigns. March 2018. Accessed August 1, 2021. https://www.cdc.gov/vitalsigns/ pdf/2018-03-vitalsigns.pdf.

69. Caven M, Malaguti A, Robinson E, Fletcher E, Dillon JF. Impact of hepatitis $\mathrm{C}$ treatment on behavioural change in relation to drug use in people who inject drugs: a systematic review. Int J Drug Policy. 2019;72:169-76.

70. Harris M, Rhodes T. Caring and curing: Considering the effects of hepatitis $\mathrm{C}$ pharmaceuticalisation in relation to nonclinical treatment outcomes. Int J Drug Policy. 2018;60:24-32. 
71. Grebely J, Hajarizadeh B, Lazarus JV, Bruneau J, Treloar C, Users INoHiS. Elimination of hepatitis c virus infection among people who use drugs: Ensuring equitable access to prevention, treatment, and care for all. Int J Drug Policy. 2019;72:1-10.

72. Mattingly TJ, Love BL, Khokhar B. Real world cost-of-illness evidence in hepatitis $C$ virus: a systematic review. PharmacoEconomics. 2020;38(9):927-39.
73. Janjua NZ, Islam N, Kuo M, et al. Identifying injection drug use and estimating population size of people who inject drugs using healthcare administrative datasets. Int J Drug Policy. 2018;55:31-39.
74. Stepanova M, Kanwal F, El-Serag HB, Younossi ZM. Insurance status and treatment candidacy of hepatitis $\mathrm{C}$ patients: analysis of population-based data from the United States. Hepatology. 2011;53(3):737-45. 